\title{
Mammalian gonadal differentiation: the pig model
}

\author{
E. Pailhoux, B. Mandon-Pepin and C. Cotinot \\ Unité de Biologie du Développement et Biotechnologies, Bâtiment J.Poly. INRA, \\ 78350 Jouy en Josas, France
}

In mammals, testicular differentiation is initiated by SRY (the sex-determining region of the $Y$ chromosome) gene expression in Sertoli cell precursors, followed by upregulation of the SOX9 gene (SRY-related HMG box gene 9). Subsequently, differentiated testis produces two hormones that induce sexual differentiation of the internal and external genital tract. Knowledge of the molecular mechanisms involved in gonadal differentiation has increased greatly over the past decade. Several genes are involved in genital ridge formation in both sexes, and others act specifically in testicular or ovarian developmental pathways. As for other mammals, relatively few data are available on the first steps of ovarian differentiation in pigs. In this review, the expression profiles of most genes known to be involved in gonadal differentiation in pigs will be presented and compared with those observed in mice. The main feature of gonadal differentiation in the pig is fetal steroidogenesis, especially cytochrome $\mathrm{P} 450$ aromatase gene organization and expression. Another specific feature of gonadal differentiation in pigs is the appearance of numerous cases of $X X$ sex-reversed animals. This intersex condition occurs as early as day 50 after coitus, during embryogenesis, and appears to be triggered genetically. It leads to a wide range of phenotypes, strikingly similar to those observed in humans. Identification of the genes involved in this pathology will improve our knowledge of mammalian gonadal differentiation and may allow the eradication of this genetic disease in pigs.

\section{Introduction}

In pigs, as in other mammals, sexual differentiation is achieved following two imbricated steps (Fig. 1). The first step leads to gonadal formation from a bipotential primordium localized at the anterior part of the mesonephros: the urogenital ridge. This developmental event, called sex determination, depends on $X X$ or $X Y$ chromosomal status determined at the time of fertilization. The presence of a single gene on the $Y$ chromosome, SRY, is sufficient to induce testicular differentiation (Sinclair et al., 1990). In females, the absence of SRY testisdetermining factor and the presence of two $X$ chromosomes allows formation of the ovaries. The second step of sexual differentiation, known as secondary differentiation, leads to the development of internal and external genitalia. The internal ducts of males and females arise from the Wolffian and Müllerian anlagen, respectively. Female differentiation has been 


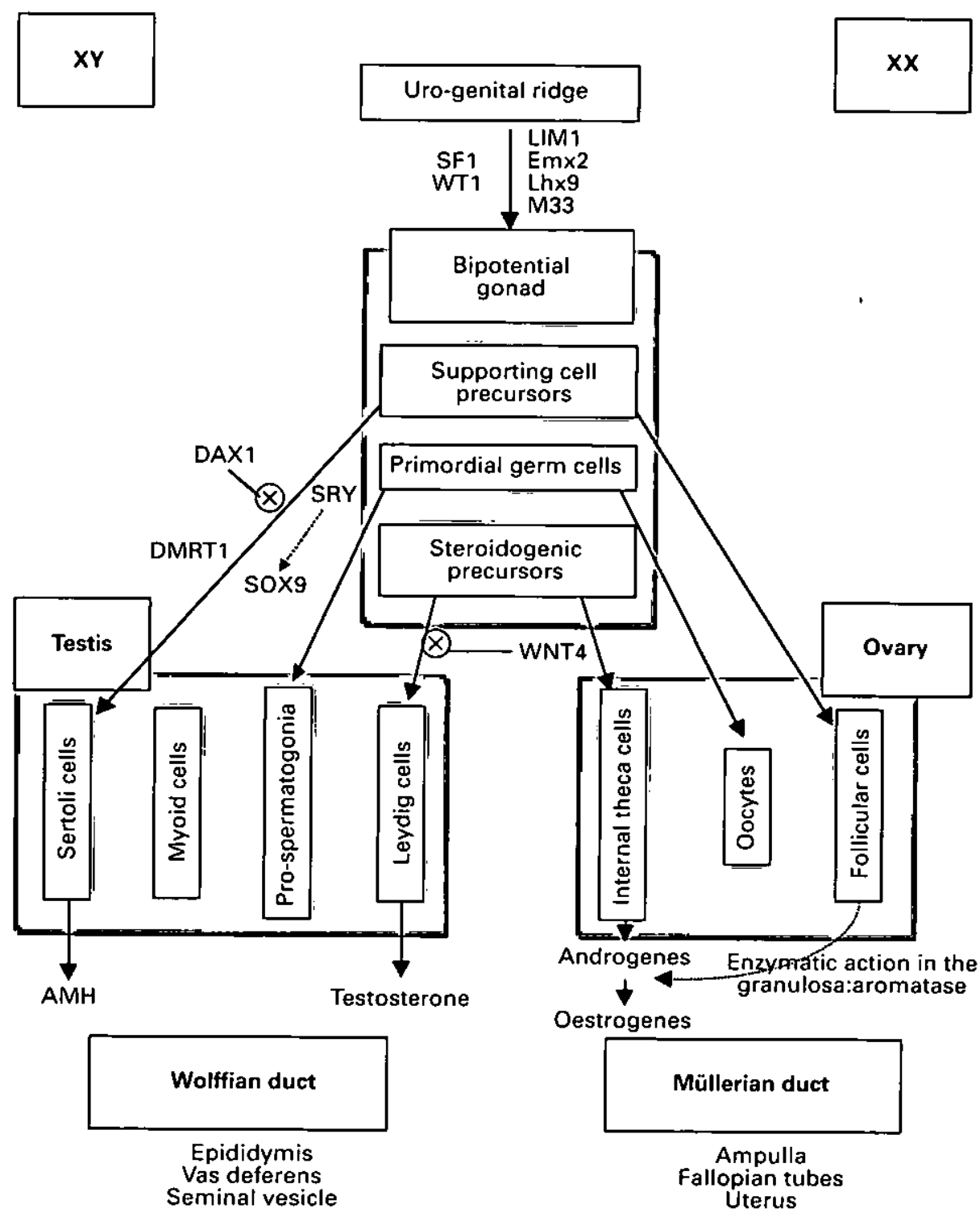

Fig. 1. Simplified representation of mammalian sexual differentiation. The left part of the figure shows male development and the right part shows the female pathway. The different steps in this developmental process are boxed, from upper to lower, chromosomal sex, gonadal sex and internal phenotypic sex. The central part of the scheme represents the sex-specific fate of the different gonadal cell types in the bipotential gonad. Their differentiated counterparts are indicated in the final gonad (testis or ovary). Myoid cells of the testis have no precursors in the bipotential gonads because they migrate from the mesonephros. Principal genes implicated in gonadal differentiation are indicated. Crossed circles depict inhibitory regulations. LIMI = Lhx1: LIM homeobox gene 1; Lhx9: LIM homeobox gene 9; Emx2: emply spiracles, Drosophila homologue 2; $M 33$ = CBX2: chromobox homologue 2, Drosophila polycomb class; SF1: steroidogenic factor 1; WT1: Wilms' tumour gene 1; DAX1: DSS-AHC critical region on the $X$ chromosome, gene 1; SRY: sex-determining region of Y chromosome; SOX9: SRY-related HMC box gene 9; DMRT1: doublesex- and Mab-3-related transcription factor 1; WNT4: winglesstype MMTV integration site family, member 4; AMH: anti-Müllerian hormone. 
considered as the default pathway, which is 'overridden' in males by two testicular hormones: the anti-Müllerian hormone (AMH) and testosterone (Jost et al., 1973). The production of $\mathrm{AMH}$ by Sertoli cells acts to suppress the Müllerian ducts, thereby preventing the formation of Fallopian tubes and uteri in males, whereas testosterone, secreted by Leydig cells, induces the formation of epididymis, vas deferens and seminal vesicles. The same process of a default pathway is involved in the formation of external genitalia (urethra, prostate gland, penis and scrotum), which differentiate from the urogenital sinus only in the presence of a male hormone: dihydrotestosterone.

This review will focus essentially on the first step of mammalian sexual differentiation, which is determined genetically. Firstly, the genes involved in this primary pathway will be described and their expression patterns in male and female pigs will be compared with those described in other species. In a second section, results concerning $X X$ sex reversal, an abnormal gonadal differentiation observed frequently in pigs, will be presented.

\section{Molecular basis of gonadal differentiation}

\section{The testis-determining factor: SRY}

All the genes involved in gonadal differentiation have been discovered during the past decade. In 1990, the first, SRY, was isolated after 25 years of research. Indeed, Ferguson-Smith (1966) predicted that after uneven crossover between sex chromosomes during male meiosis, the testis-determining factor (TDF) could translocate from $Y$ to $X$ and cause sex reversal in humans. After numerous genetic studies on sex-reversed patients, a candidate gene was found in a $35 \mathrm{~kb}$ Y DNA fragment present in an XX male patient: SRY (Sinclair et al., 1990). Thereafter, two pieces of experimental evidence were collected proving that SRY is TDF: (i) the open reading frame of $S R Y$ presents a mutation in $X Y$ female patients with gonadal dysgenesis (Cameron and Sinclair, 1997); and (ii) a $14.6 \mathrm{~kb}$ fragment containing the murine homologue (Sry) reverses the sex of XX mice when added by transgenesis (Koopman et al., 1991). This intronless gene has been found in most mammalian species and represents the master gene in testicular differentiation. In pigs it has been located in the distal portion of the short arm of the $Y$ chromosome (p12-p13), which is a conserved chromosomal position compared with that of humans (Yang et al., 1993). SRY encodes a nuclear factor encompassing a conserved DNA binding domain of 79 amino acids (HMG box). Surprisingly, outside this domain, the SRY protein is poorly conserved among mammals, a fact that is particularly true for humans and mice (Whitfield et al., 1993). Despite 10 years of research, the biological target of SRY and its molecular mechanism of action remain unknown.

\section{The other genes}

Sex determination appears to be a complex process involving two types of genes: some of the genes are implicated in the formation of the genital ridges in both sexes, whereas others are involved specifically in testis or ovary differentiation. To date, six genes encoding transcription factors have been classified in the first group: Wilms' tumour gene 1 (WT1), steroidogenic factor 1 (SF1), three homeobox genes (LIM1, Emx2 and Lhx9) and M33, a mouse homologue of the Drosophila polycomb genes. Five genes belong to the second group: the testis determining factor SRY, the SRY-related HMG box gene 9 (SOX9), the X-linked gene DAX1, DMRT1 and a gene of the Wnt/Wingless family WNT4.

Genes involved in early gonadogenesis. WT1 was first discovered in humans by genetic analysis of patients affected by renal failure (Wilms' tumour) associated with an XY sex 
reversal phenotype (Gessler et al., 1990; Pelletier et al., 1991). The implication of WT1 in urogenital ridge formation was demonstrated clearly by knockout experiments in mice (Kreidberg et al., 1993). Indeed, homozygous mutant embryos revealed failure in gonad and kidney development. The 10 exon WT1 gene contains two alternative spliced regions, one in exon 5 and a second in exon 9, giving rise to the addition or suppression of three amino acids: lysine-threonine-serine: KTS (Haber et al., 1991). Therefore, WT1 encodes four distinct transcription factors, each containing four zinc finger domains. In addition to their DNA binding activity, WT1 proteins might also bind RNA and act as post-transcriptional regulators (Caricasole et al., 1996; Bardeesy and Pelletier, 1998). WT1 transcripts are expressed very early in the mesonephros, then in the genital ridges and their expression persists in the gonad of both sexes throughout life (Pritchard-Jones et al., 1990; Payen et al., 1996). In addition to the involvement of WT1 in genital ridge formation, WT1 isoform without KTS can regulate the gene encoding AMH (Nachtigal et al., 1998). The biological significance of isoform ratios (with or without KTS) has been brought to light by studying patients with Frasier syndrome (Barbaux et al., 1997). In this syndrome, XY sex reversal is a consequence of intronic mutation preventing the production of the KTS-containing isoforms, thereby altering the isoform ratios in heterozygous affected patients. In conclusion, according to the expression pattern and the complexity of this gene, it is clear that WT1 is a key factor in gonadal formation and testis differentiation in mammals.

The nuclear hormone receptor SF1 homologous to the Drosophila fushi-tarazu factor 1 ( $F t z-F 1$ ), also termed Ad4BP (adrenal 4 binding protein), was first isolated as a common regulator of cytochrome $\mathrm{P} 450$ steroid hydroxylases in the gonads and adrenal cortex (Lala et al., 1992; Morohashi et al., 1992). In the testis, expression of SF1 has been identified in Leydig cells as well as in Sertoli cells, where it contributes to maintaining high AMH expression (Shen et al., 1994; Arango et al., 1999). Another critical role in gonadal and adrenal development has been demonstrated by knockout experiments: mice lacking SF1 are devoid of gonads and adrenal glands (Luo et al., 1994). Recently, a similar phenotype has been described in an XY woman patient harbouring a heterozygous 2 bp substitution in the DNA binding domain of SF1 (Achermann et al., 1999). Hence, it is clear that SF1 is implicated at numerous steps in sexual differentiation as it regulates a large array of genes involved in gonadal formation and hormonal synthesis.

In addition to WT1 and SF1, four other genes involved in urogenital ridge formation have been identified by knockout experiments in mice. Three of these genes belong to the homeobox gene family. Lhx9 invalidation results in failure in gonad formation without any additional major developmental defects (Birk et al., 2000). Invalidation of the other two genes leads to a more marked change in the phenotype, with an absence of head structures for LIM1, and of kidneys and gonads for LIM1 and Emx2 (Shawlot and Behringer, 1995; Miyamoto et al., 1997). The last gene in this group, M33, is one of the Drosophila polycomb genes. M33 null mice underwent a significant delay in gonadogenesis, leading to male-to-female sex reversal in XY fetuses (Katoh-Fukui et al., 1998). The involvement of these genes in urogenital ridge formation has been demonstrated clearly in gene disruption experiments, but this strategy makes it impossible to reveal other putative functions later in sexual differentiation (such as WT1 and SF1). Conditional knockout will be needed to gain further information.

Sex differentiating genes. The $Y$ specific gene SRY initiates a cascade of gene regulations resulting in maleness. One of the most important genes downstream from SRY is SOX9, which encodes a key transcription factor for testicular differentiation. SOX9 was first isolated by studying patients with a bone developmental defect, campomelic dysplasia, associated with $75 \%$ of $X Y$ individuals with a male-to-female sex reversal (Foster et al., 1994; Wagner et al., 
1994). The structure of SOX9 is that of a typical transcription factor with a DNA binding domain (HMG box) and a transcriptional trans-activating domain (Südbeck et al., 1996). From an evolutionary viewpoint, the structure and expression pattern of SOX9 appear to be highly conserved among mammals as well as in other vertebrates, such as birds and reptiles (Kent et al., 1996; Morais da Silva et al., 1996; Western et al., 1999). A high expression of SOX9 is always correlated with testicular differentiation, independent of the presence of SRY. Abnormal upregulation of SOX9 in XX individuals is associated with female-to-male sex reversal in humans and mice (Huang et al., 1999; Bishop et al., 2000). It is now clear that SOX9 lies at a crucial step in testis formation and that progress in the understanding of this differentiation pathway could result from studies on its transcriptional regulation. However, defects in the expression of SOX9 leading to sex reversal indicate that there may be long range regulatory elements distributed as far as $1 \mathrm{Mb}$ upstream from the coding region of the gene (Wunderle et al., 1998; Pfeifer et al., 1999). This fact has also been pointed out in XX mice with the description of the Odsex (ocular degeneration with sex reversal) mutation consisting of a $150 \mathrm{~kb}$ deletion localized at about $1 \mathrm{Mb}$ upstream from Sox9. The authors conclude that the deletion encloses a female specific repressor binding site in this $5^{\prime}$ region (Bishop et al., 2000), strengthening the suspicion that male specific genes such as SOX9 may be repressed in XX individuals (McElreavey et al., 1993).

One putative repressor of male genes was discovered in 1994 by studying XY sex-reversed female patients harbouring a partial duplication (band p21) of their X chromosome (Bardoni et al., 1994). In this dosage-sensitive sex reversal region (DSS), the DAX1 gene (DSS-AHC critical region on the $X$ chromosome) appears to be the best candidate for triggering the absence of testicular differentiation by acting antagonistically to SRY (Swain et al., 1998). This possibility was confirmed by the characterization of the Dax-1 expression pattern in mice, which was expressed more highly in ovaries than in testes (Swain et al., 1996). According to all these results, DAX1 was assumed to be a potential ovarian differentiating factor until the observation of Dax-1-null mice. Surprisingly, the disruption of Dax-1 in female mice does not prevent ovarian differentiation or fertility (Yu et al., 1998). In contrast, male spermatogenesis is affected in XY Dax-1 $-\mathrm{Y}$ mice.

A true ovarian determining gene was discovered by knockout experiments of Wnt-4, a signalling protein of the Wnt/Wingless family (Vainio et al., 1999). Homozygous disruption of Wnt-4 triggers the development of Leydig cells and steroidogenesis in female gonads. In contrast, sexual differentiation in $W n t-4-1-$ males appears to be normal at birth. The female dimorphic expression pattern of Wnt-4 in mice also provides evidence for an ovarydifferentiating role of this gene (Vainio et al., 1999).

In conclusion, many factors involved in gonadal differentiation have been isolated and characterized over the past decade, but there may be other factors that are still unknown. For example, the genetic aetiology of many cases of sex reversal in humans and mammalian species remains to be elucidated and does not appear to be the result of mutations within known genes (Vaiman and Pailhoux, 2000). Monosomic deletions of chromosome 9p associated with male-to-female $X Y$ sex reversal in humans have indicated the possible role of DMRT1 in testis differentiation (Calvari et al., 2000; Ottolenghi et al., 2000). This gene, which is homologous to doublesex in Drosophila and mab-3 in Caenorhabditis (Raymond et al., 1998), plays a crucial role in testis formation in reptiles and birds (Raymond et al., 1999; Kettlewell et al., 2000).

\section{Relationships among sex differentiating genes (Fig. 2)}

Many studies have focussed on transcriptional regulation of the $\mathrm{AMH}$ gene. Indeed, $\mathrm{AMH}$ is the first hormone secreted by the differentiated testis. Two binding sites, one for SF1 and the 


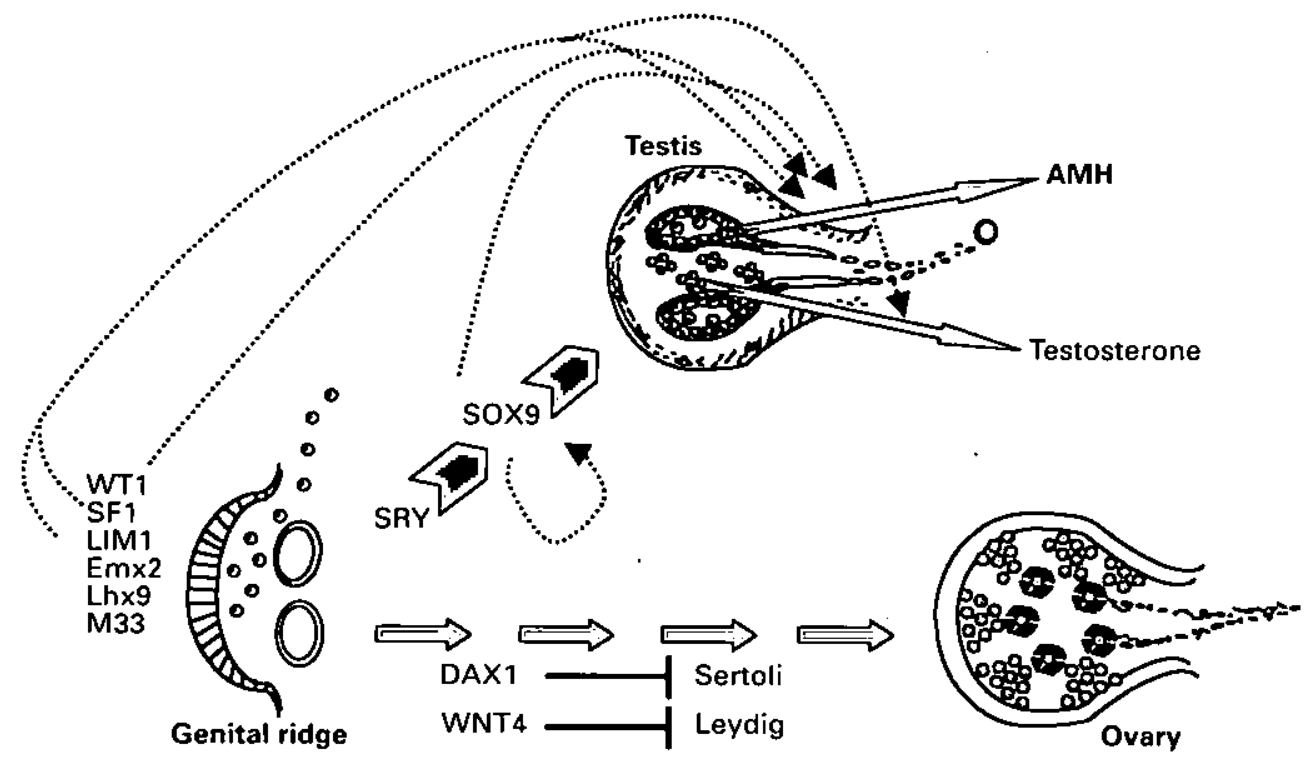

Fig. 2. Gene epistasis in gonadal formation. The upper part represents the male pathway initiated by SRY, with SOX9 as a key testicular factor. Dotted arrows indicate its role in AMH upregulation. AMH expression is also controlled positively by SF1 and WT1. The lower part shows the female pathway, including two male pathway inhibitors, DAX1 and WNT4. The six genes on the left are involved in genital ridge formation. LIM1 = Lhx1: LIM homeobox gene 1; Lhx9: LIM homeobox gene 9; Emx2: empty spiracles, Drosophila homologue 2; M33 = CBX2: chromobox homologue 2, Drosophila polycomb class; SF1: steroidogenic factor 1; WT1: Wilms' tumour gene 1; DAX1: DSS-AHC critical region on the $X$ chromosome, gene 1; SRY: sex-determining region of $Y$ chromosome; SOX9: SRYrelated HMG box gene 9; WNT4: wingless-type MMTV integration site family, member 4; AMH: anti-Müllerian hormone.

other for SOX9, are highly conserved in the promoter region of the $\mathrm{AMH}$ gene among different mammalian species (Shen et al., 1994). By targeted mutagenesis of these binding sites in vivo, it has been shown that, in mice, SOX9 triggers AMH expression and SF1 enhances it (Arango et al., 1999). DAX1 and WT1 (-KTS) might also act as negative and positive modulators on AMH transcription through protein interaction with SF1 (Nachtigal et al., 1998).

In conclusion, SOX9 is a key gene in mammalian sexual differentiation. Some questions remain to be answered. How is this gene upregulated in males and downregulated in females? What is the link between SRY and SOX9? Also, other than AMH, what male genes are regulated specifically by SOX 9 ?

\section{Gonadal differentiation: a cellular viewpoint}

During the past 4 years, interesting results have been obtained using a co-culture system of gonads with mesonephri from a transgenic strain ubiquitously expressing $\beta$-galactosidase. Firstly, it has been shown that migration of mesonephric cells takes place into $X Y$ but not $X X$ gonads from day 11.5 to day 16.5 after coitus in mice (Martineau et al., 1997). The signal that triggers migration operates over long distances and behaves as a chemoattractant. By culturing $X X$ gonads with $X Y$ gonads at their surfaces, as a sandwich, mesonephric cell 
migration into the $X X$ tissue took place. After this migration, the $X X$ gonads organized cord structures and acquired male-specific patterns of gene expression (Tilmann and Capel, 1999). The migrating mesonephric cells give rise to three types of cell population in $X Y$ gonads: myoid, endothelial and some closely associated with endothelial cells. Finally, by using XX gonads transgenic for SRY, it has been shown that this migration event depends on the SRY gene and represents the earliest physiological sign of SRY action (Capel et al., 1999).

\section{The pig: a particular model of mammals?}

To date, most of the gene expression patterns described have been observed in mice. In pigs, four studies present the time course of sex-determining genes during gonadal development (Daneau et al., 1996; Parma et al., 1997, 1999; Pilon et al., 1998). The main results of these studies are summarized (Fig. 3 ) and compared with expression profiles in mice. No significant differences are noticeable for three genes: SOX9, DAX1 and AMH. There are three notable differences between these two species, two in males and one in females. In female mice, SF1 expression is stopped between germ cell meiosis (day 13.5 after coitus) and the beginning of folliculogenesis (day 18.5 after coitus) (Ikeda et al., 1994). In pigs, SF1 is expressed continuously in gonads of both sexes from the time of formation of genital ridges (day 23 after coitus). Different levels of expression between sexes (high in males versus low in females) have been found using northern blot analysis at later stages (days 45-52 after coitus) (Pilon et al., 1998). In mice, transcription of the SRY gene has been detected during a very short period of 2 days (days 10.5-12.5 after coitus) (Jeske et al., 1995). Conversely, in pigs, SRY is expressed over a longer period of about 3 weeks. Expression persists $>2$ weeks after the first sign of Sertoli cell differentiation (day 28 after coitus in pigs) (Parma et al., 1999). The role of this persistence of SRY in domestic species is unknown but it could suggest the involvement of this gene in other developmental testicular processes, such as inhibition of male germ cell meiosis. The main difference is in the expression of aromatase. In pigs, P450 aromatase transcripts are detected very early in testicular differentiation, at the same time as AMH expression (Parma et al., 1999). In mice, there is no expression of aromatase until birth in both sexes and in sheep and goats an expression peak is observed between gonadal differentiation and germ cell meiosis, but only in the female fetuses (Payen et al., 1996; E. Pailhoux, personal observation). Of the species studied, the pig appears to be unique as far as P450 aromatase is concerned. There are three distinct functional genes encoding three isoforms (type I: ovary; type II: placenta; and type III: embryo), with presumed differences in substrate specificities, expression, activity and mode of regulation (Graddy et al., 2000). The testicular isoform appears to be the same as that expressed in the adult ovary (Conley et al., 1996). The testicular isoform also appears to be active, as oestrone sulphate was first detected in male pig fetuses at day 31 after coitus (Raeside et al., 1993). This fetal production of oestrogens by the testis remains poorly understood. One putative cellular target could be the gonocytes, as proposed by Parma et al. (1999). In addition to aromatase, it seems that the entire fetal steroidogenic pathway is different in pigs compared with other mammalian species. We recently tested the expression of $3 \beta$-hydroxysteroid dehydrogenase $(3 \beta-H S D)$ in gonads of male, female and intersex fetuses at days 50 and 70 after coitus and found similar high expression in all the samples tested. Also surprising was the expression profile of WNT4 (Fig. 5), which appears to be slightly higher in females, although a significant expression was also detected in males, in contrast to the case in mice. In conclusion, it appears that the specific steroidogenesis observed in pigs must be investigated further to gain a better understanding of the role these hormones play in the formation and maintenance of functional gonads and reproductive organs. 


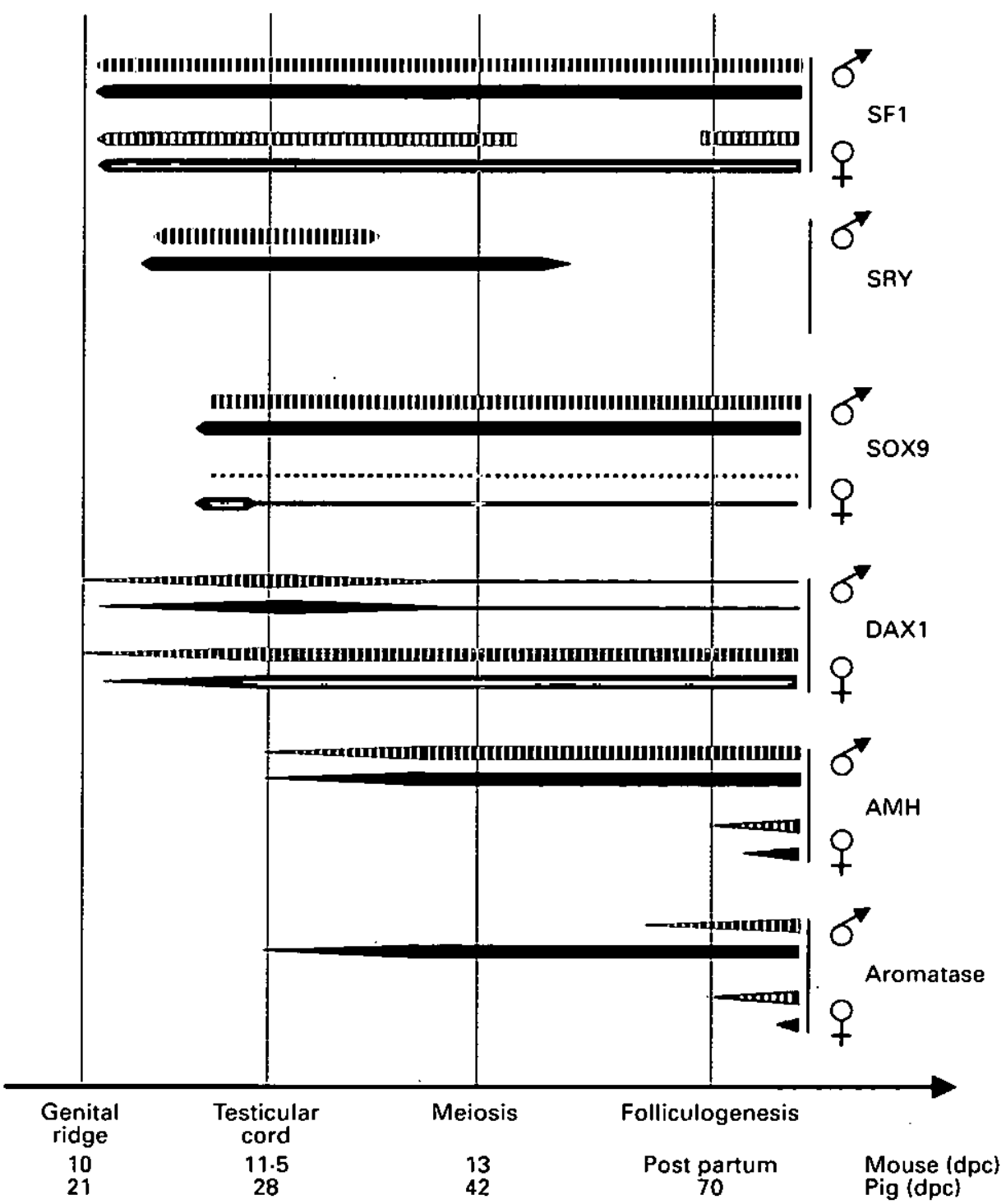

Fig. 3. Time course of gene expression during mouse and pig gonadal differentiation. The width of the lines is proportional to the relative expression. For each gene indicated on the right, the expression in gonads of male mice (striped black), male pigs (black), female mice (striped grey) and female pigs (grey) is shown during four main developmental processes, as indicated under the arrow symbolizing the time course of development. dpc: indicates the days after coitus at which these developmental processes occur. SF1: steroidogenic factor 1; SRY: sex-determining region of $Y$ chromosome; SOX9: SRY-related HMG box gene 9; DAX1: DSSAHC critical region on the $X$ chromosome, gene 1; AMH: anti-Müllerian hormone.

\section{Genes involved in ovary development}

In the presence of two $X$ chromosomes, the indifferent embryonic gonad develops into an ovary. Ovarian differentiation, germ cell meiosis and folliculogenesis begin during fetal life in pigs. Other key events, such as follicular growth and atresia, which occur throughout 


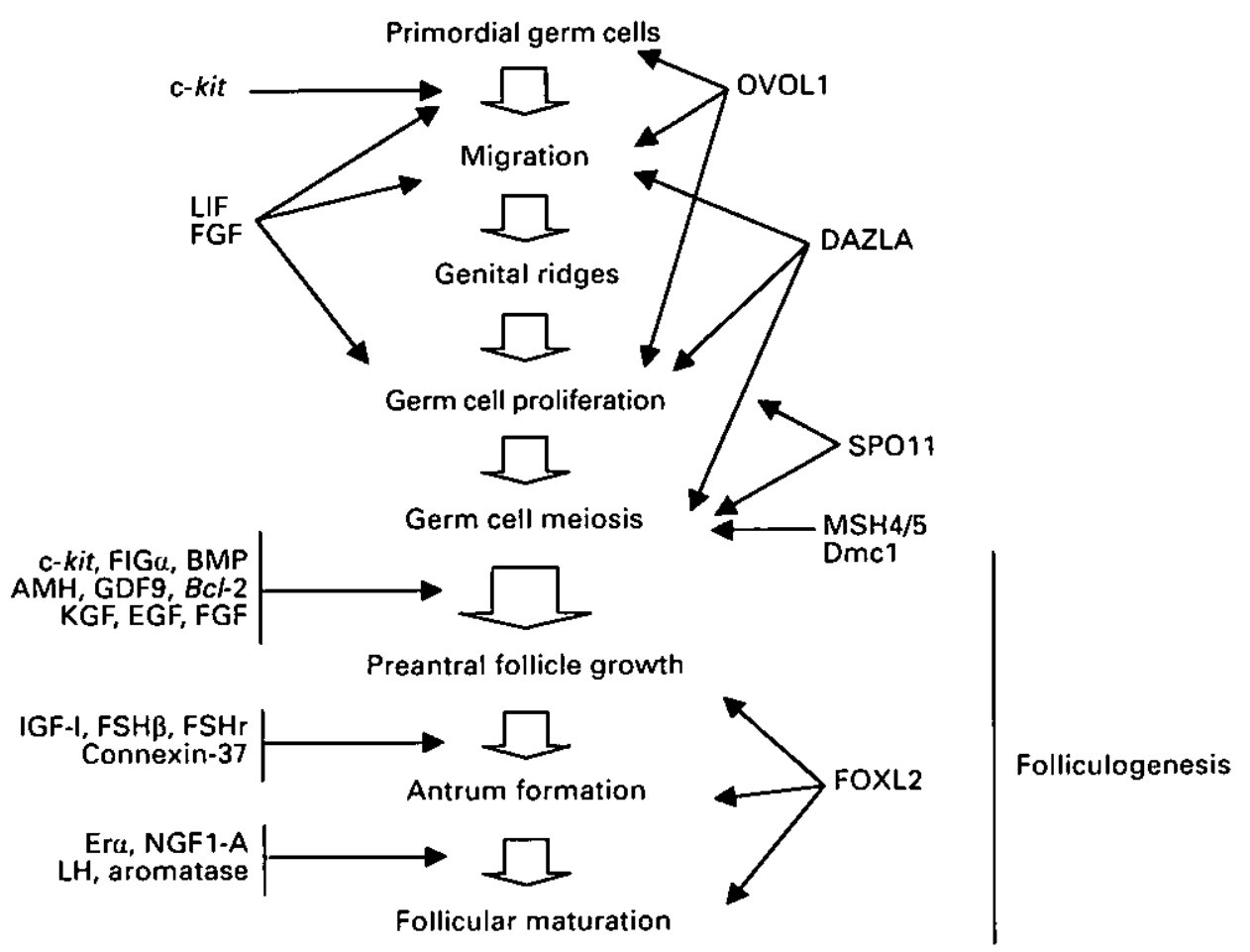

Fig. 4. Schematic representation of ovarian differentiation and function. Four main steps of germ cell life are represented (migration, proliferation, meiosis and maturation). A nonexhaustive list of factors involved in different steps is indicated on both sides of the diagram. OVOL1: OVO, Drosophila homologue-like 1; LIF: leukaemia inhibitory factor; FGF: fibroblast growth factor; DAZLA: deleted in azoospermia-like, autosomal; SPO11: Saccharomyces cerevisiae homologue of SPO11; MSH4/5: MutS Escherichia coli homologue 4/5; Dmc1: disrupted meiotic CDNA 1, yeast homologue; FOXL2: forkhead transcription factor L2; FIG $\alpha$ : factor in the germ line, alpha; BMP: bone morphogenetic protein; AMH: anti-Müllerian hormone; GDF9: growth/differentiation factor 9; BCl-2: B-cell Cli/lymphoma 2; KGF: keratinocyte growth factor; EGF: epidermal growth factor; IGF-l: insulin-like growth factor I; FSHB: follicle-stimulating hormone, beta polypeptide; FSHr: FSH receptor; Ero: oestrogen receptor alpha; NGF1-A: nerve growth factor $1-\mathrm{A}$; and $\mathrm{LH}$ : luteinizing hormone.

prepubertal and reproductive life, are also initiated during fetal life. Four major phases can be distinguished: migration, proliferation and meiosis of the germ cells, and folliculogenesis. These steps are under the control of several transcription factors, growth and paracrine factors, and hormones (Fig. 4).

In pigs, urogenital ridge formation begins at day 21 after coitus (Pelliniemi, 1985). The migration and proliferation of germ cells depend on co-ordinated expression and interaction of different genes. Two factors: c-kit and c-kit ligand (stem cell factor; SCF) play a central role in the migration and colonization of germ cells to the developing genital ridge. SCF controls the early germ-line population and is an essential requirement for primordial germ cell survival (Godin et al., 1991). Leukaemia inhibitory factor (LIF) is crucial for primary germ cell development (Donovan, 1994). It can stimulate primary germ cell proliferation in culture and may regulate primordial germ cell survival and proliferation in vivo. Apoptosis is responsible for primordial germ cell attrition in the developing fetal ovary. LIF might support primordial 
germ cell survival by preventing primordial germ cell apoptosis (De Felici and Pesce, 1994). Another gene of interest during this step is the DAZLA gene. Indeed, the disruption of the DAZLA gene leads to a loss of germ cells and complete absence of male and female gamete production (Ruggiu et al., 1997). DAZLA transcripts are localized in germ cells before meiosis and at the time meiosis begins. In the ovary, transcripts are not restricted to germ cells, but are found in somatic cells of primordial follicles (granulosa) as well.

Several genes have been shown to be involved in germ cell meiosis from day 42 after coitus in pigs. As oocytes transit from pachytene to diplotene before arresting, DNA repair proteins and other factors are required for proper chromosome alignment and recombination. Oogonia lacking MSH5 (homologue of bacterial MutS) or DMC1 (homologue of RecA) do not complete meiosis and are invariably lost from the ovary before diplotene. Null mice for Msh5 (Edelmann et al., 1999) are viable but sterile. Meiosis in these mice is affected due to disruption of chromosome pairing in prophase I. The ovaries of Msh5 -/- females are normal in size at birth but degenerate progressively to become rudimentary, concomitant with the decrease in the number of oocytes from before day 3 post partum until adulthood. Null mutation of Dmc1 genes showed that homozygous mutant males and females are sterile, with arrest of gametogenesis in the first meiotic prophase (Habu et al., 1996). In Dmc1 -/- female mice, normal differentiation of oogenesis was aborted in embryos and germ cells disappeared in the adult ovary.

Primordial follicles are formed perinatally in mammalian ovaries and the first appears at about day 70 after coitus in pigs. Folliculogenesis requires careful orchestration of developmental programmes in germ and somatic cells, as well as the interactions between them. In the initial stage of folliculogenesis, paracrine factors promote growth of the oocyte and adjacent somatic cells. FIG $\alpha$ (factor in the germ line alpha), a germline cell-specific factor (Soyal et al., 2000), is crucial for the initial formation of primordial follicles. Mouse lines lacking FIG $\alpha$ have primordial follicles that are not formed at birth and a massive depletion of oocytes, resulting in shrunken ovaries and female sterility. In addition, many growth factors, fibroblast growth factor 8 (FGF8) and several members of the transforming growth factor $\beta$ (TGF $\beta$ ) family have been implicated in regulating early folliculogenesis. One factor, antiMüllerian hormone (AMH), is expressed in granulosa cells surrounding oocytes and has been implicated in the recruitment of primordial follicles into the growth phase of folliculogenesis (Durlinger et al., 1999). Other members of the TGF $\beta$ family, GDF9A (growth/differentiation factor 9) and BMP15 (bone morphogenetic protein 15), are first expressed in oocytes in primary follicles (McGrath et al., 1995; Dube et al., 1998). Female mice deficient in GDF9A are infertile because of an early block in folliculogenesis at the type $3 \mathrm{~b}$ primary follicle stage. BMP15 is an oocyte-derived growth factor essential for female fertility. Natural mutation in this gene (Inverdale sheep carrying FecXI mutation) causes both increased ovulation rate and infertility phenotypes in a dosage-sensitive manner (Galloway et al., 2000). Finally, the absence of gonadotrophins leads to atretic follicles that disappear from the ovary.

The female pig gonad remains undifferentiated histologically until day 28 after coitus and final histological differentiation of the ovary is achieved by day 44 after coitus when the cortical cords have been organized and the medullary cords have degenerated (Pelliniemi and Lauteala, 1981). We analysed temporal expression of some of these genes involved in mammalian ovary development by RT-PCR. As examples, the results of three of these genes presenting typical expression profiles are summarized (Fig. 5). The ovarian-determining gene WNT4 was expressed as early as day 37 after coitus and throughout fetal life in both sexes, with a relatively higher expression in females. DMC1, which is essential for meiotic recombination, was first expressed during meiosis, between day 45 and day 52 after coitus, began to decrease at day 70 after coitus (last studied stage during fetal life) and was expressed 


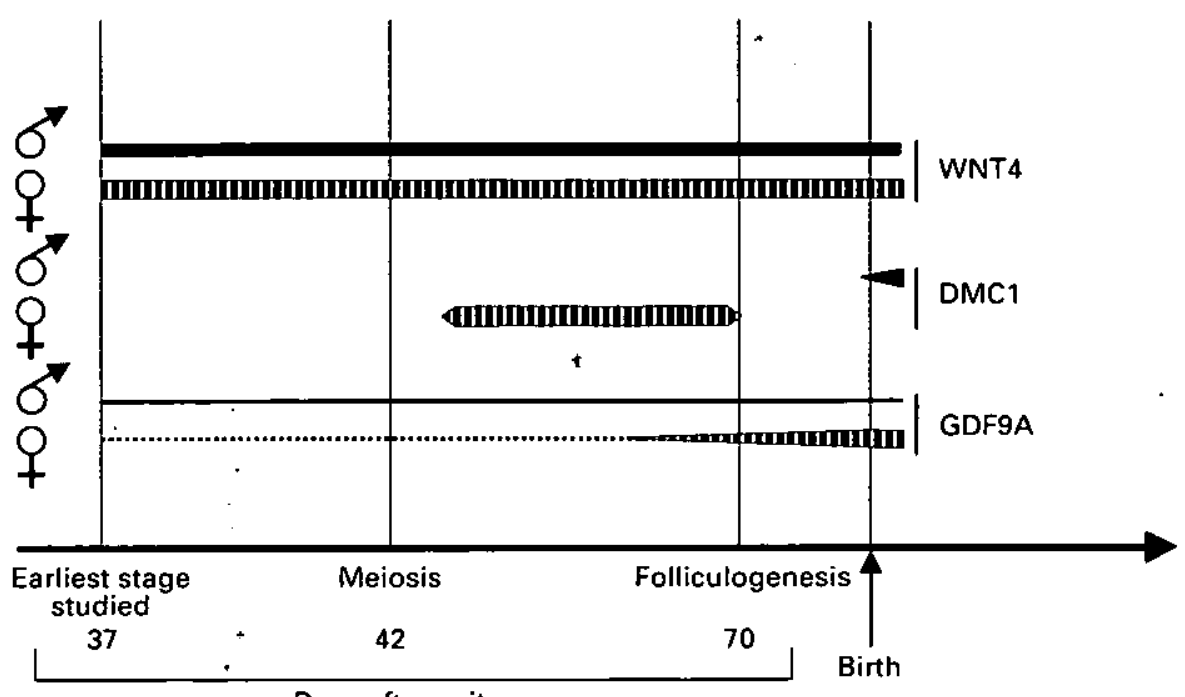

Days after coitus

Fig. 5. Example of expression profiles of ovarian genes in pigs. These genes are involved in three different developmental steps: WNT4: ovarian differentiation; DMC1: germ cell meiosis; GDF-9A: folliculogenesis. The width of the lines is proportional to the expression. For each gene, the expression is shown for males (full line) and females (striped line). WNT4: wingless-type MMTV integration site family, member 4; DMC1: disrupted meiotic cDNA 1; GDF9A: growth/differentiation factor $9 A$.

in gonads of 5-week-old males. GDF9A, described as an oocyte-derived paracrine factor important for growth of follicles beyond the primary stage, increased at the beginning of folliculogenesis (day 65 after coitus).

These studies demonstrate that several genes, whether restricted in their expression to the ovary or expressed preferentially in the ovary, constitute critical determinants in ovarian development. Further investigations are also in progress, such as suppressive subtractive hybridization during the different stages of pig fetal ovarian development to isolate genes that are expressed differentially at key stages of ovarian development (before meiosis, during meiosis and during folliculogenesis).

\section{Anomalous sexual development: sex reversal}

In parallel with the classic scheme of sex differentiation in mammals, exceptions exist where $X X$ individuals develop testes in the absence of the $Y$ chromosome and, conversely, $X Y$ individuals without testes have been described. Such individuals have been observed in numerous mammalian species including humans, pigs, goats, horses, dogs, mice, marsupials and moles, and are called sex-reserved or intersexes (Pailhoux et al., 1994a,b; Sanchez et al., 1996; Whitworth et al., 1996; Meyers-Wallen et al., 1999; Bishop et al., 2000; Buoen et al., 2000; Sarafoglou and Ostrer, 2000). Some of these individuals result from mutations in the SRY gene ( $X Y$ female) or from translocation of SRY to the $X$ chromosome or autosomes (XX male). However, most sex-reversed individuals result from alterations of $X$-linked or autosomal genes remaining for the most part unknown. The genes known to be involved in sex determination, such as SRY, WT-1, DAX-1 and SOX9, have been isolated by genetic analysis of sex-reversed patients. 
In pigs, the frequency of intersexuality ranges from 0.1 to $0.5 \%$ of females and may reach up to $20 \%$ in isolated herds. The animals described are mainly adults that were detected either by the breeder because of abnormal external genitalia or at slaughter through discovery of one or two abdominal testes. At slaughter, the incidence of intersexuality is $>0.2 \%$ of the total European pig population. In practical terms, instances of intersexuality represent a source of direct loss in the breeding herd resulting from sterility, genital infections reducing growth and viability and downgrading of carcasses for so-called boar taint. In addition, such animals may provoke losses due to their aggressive behaviour.

Intersex pigs are masculinized genetic females with a 38, XX chromosome constitution. We studied about 50 adult animals from an experimental breeding herd at INRA (Institut National de la Recherche Agronomique), where about 1\% of females are intersexes, to elucidate the genetic aetiology of the pig sex reversal condition. PCR was used to test the DNA from blood and gonadal biopsies of intersex animals for the presence of cryptic $Y$ chromosome-specific sequences, particularly the SRY gene. Intersex pigs result from three situations: the presence of $X X$ and $X Y$ cells within the same animal $(4 \%)$; the presence of a small fragment of the $Y$ chromosome (containing the SRY gene) in $X X$ individuals $(2 \%)$; and the presence of an autosomal or $X$-linked mutation affecting genes in the sex-determining pathway or mimicking their effects (94\%) (Pailhoux et al., 1997).

A genetic approach was attempted using genome scanning of resource families to isolate genes involved in intersexuality in pigs. Analyses indicate that sex reversal in this species is controlled multigenically and five regions of the genome appear to be involved ( $E$. Pailhoux, personal observation). Some of these regions correspond to regions described previously in humans, which also confer abnormal sex determination.

Phenotypically, all the animals studied ranged from true hermaphrodites $(48 \%)$ to males with $(50 \%)$ and without $(2 \%)$ ambiguities. True hermaphrodites with both testicular and ovarian tissue in the same animal or in the same gonad have been observed and a few rare cases of pregnancy in these hermaphrodite sows have been obtained (Pailhoux et al., 1997). Of the 50 animals observed, only one was a male without ambiguities. This phenotype, which was characterized by an external and internal male type genitalia, has not been described previously in pigs. The only visible defect was a unilateral cryptorchidism. From histological observations of gonadal biopsies, intersex gonads can be divided into different phenotypes. The most primitive type consists of unorganized tissue with neither ovarian nor testicular structures. The second type contains cords in interstitial stroma and thus resembles the sexually indifferent phase of embryonic gonadal differentiation. The third type occurs as a testis or an ovotestis and resembles the normal testis but with cords that are thinner and devoid of germ cells. The fourth type is similar but more rudimentary. The fifth occurs as an ovary or an ovotestis and consists of variable ovarian tissue (Pailhoux et al., 1997). This broad variability of gonadal phenotypes is one of the main features of this pathology. The precise classification of the different cases of intersexuality in pigs reveals strong similarity with observations in human sex-reversed patients.

Pig fetuses were studied during gonadal development to determine the onset of the pathology (Fig. 6). The fetuses were obtained by crossing parents that had produced intersexes previously in their progeny. These molecular and histological investigations revealed that as early as day 50 after coitus, intersex gonads could differ from normal ovaries and present expression profiles of the male type for $\mathrm{SOX} 9, \mathrm{AMH}$ and $\mathrm{P} 450$ aromatase genes. Variability in gonadal phenotypes was observed at all the developmental stages tested, even within the same animal. The degeneration of germ cells observed in the testicular portion of all the intersex gonads was observed just after birth. The development of both non-functional ovaries and testis in intersex individuals with complete female chromosomes indicates that defective 

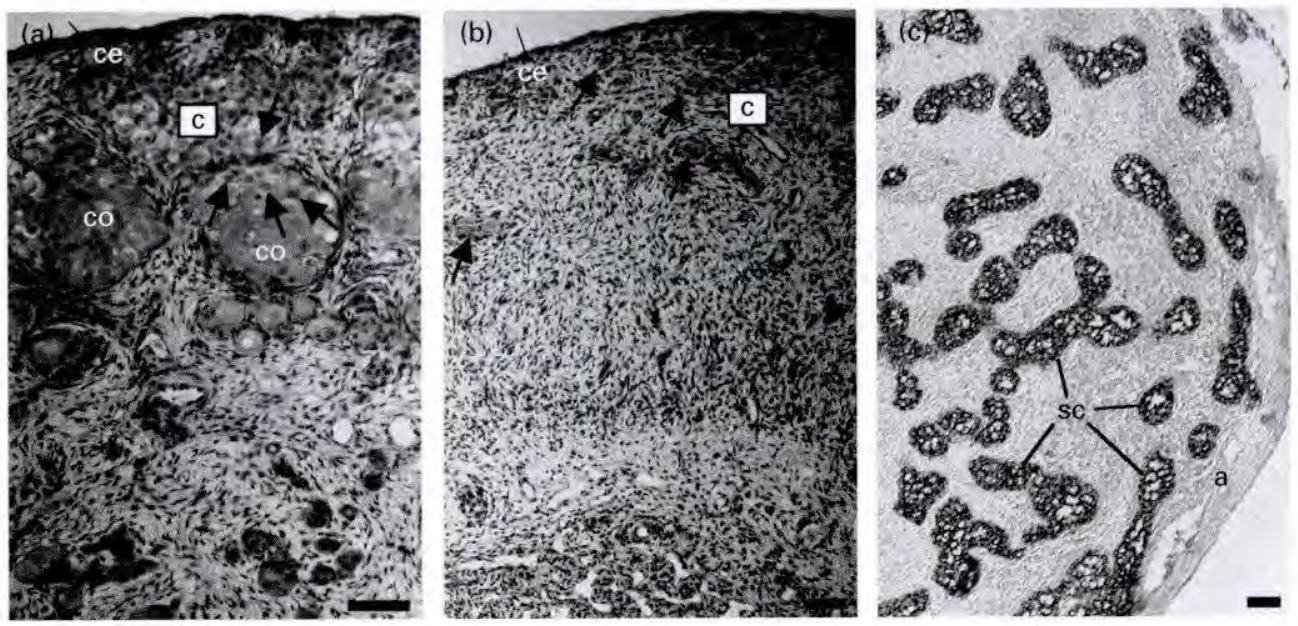

Fig. 6. Light micrograph of three gonadal sections from XX pigs. (a) Normal ovary at day 70 after coitus. (b) Ovary of an intersex pig at day 70 after coitus. Note the hypoplasia of the ovarian cortex associated with the reduction of germ cell number. (c) Immunohistological detection of antiMüllerian hormone $(\mathrm{AMH})$ in seminiferous tubules of a fetal $\mathrm{XX}$ sex-reversed gonad at day 50 after coitus. ce: coelomic epithelium; c: ovarian cortex; co: ovigerous cord; sc: seminiferous cord. The arrows show the germ cells. Scale bars represent $50 \mu \mathrm{m}$.

genes are involved in normal females, both in inhibition of male gonadal differentiation and maintenance of ovarian differentiation. Indeed, the ovarian pathway had been initiated in these gonads, but was altered and gave rise to severe ovarian dysfunction leading in some cases to complete transdifferentiation. Molecular identification of the genes involved in this pathology of XX sex reversal will greatly increase our understanding of sex determination and gonadal differentiation in mammals.

\section{Conclusion}

Our knowledge of the molecular mechanisms involved in mammalian gonadal differentiation has been improved greatly by the isolation and study of numerous genes. To date, the male pathway has been better characterized as a result of the discovery of two main genes: the testis-determining factor SRY and the Sertoli cell-specific factor SOX9. There is little information on the ovarian-determining pathway and very few factors have been identified. WNT4 is one factor that has been identified and appears to be an inhibitory testis factor. Likewise, two mutations (odsex in mice and polled intersex syndrome in goats) are indicative of the existence of this type of factor. Indeed, they reveal that XX sex reversal could be the result of suppression of such inhibitory effects. Similarly, investigations of pig intersexuality could give some insight into this type of gene. A better understanding of this pathology in pigs will also offer breeders the possibility of eradicating intersexuality and enhancing female fertility. Indeed, genes involved in ovarian sex reversal are likely to be critical factors in ovarian differentiation and function. Other interesting approaches for isolating ovarianspecific genes are being produced by the new transcriptome technologies. The systematic differential screening of transcripts involved in the crucial steps of ovarian differentiation (meiosis, folliculogenesis) along with delimitation of chromosomal segments implicated in reproductive quantitative trait loci will certainly improve the control of female fertility. 
The authors would like to acknowledge the help of their collaborators in studies of pig intersexuality: A. Barbosa, J. Bussière, P. Dando, M. Fellous, M. Georges, J-M. Gogué, J. Gruand, P. Guillouet, C. Legault, C. Nezer, P. Parma, L. Pelliniemi, N. Servel and B. Vigier.

\section{References}

Achermann JC, Ito M, Ito $\mathrm{M}$, Hindmarsh PC and Jameson JL (1999) A mutation in the gene encoding steroidogenic factor-1 causes $X Y$ sex reversal and adrenal failure in humans Nature Genetics 22 125-126

Arango NA, Lovell-Badge $\mathbf{R}$ and Behringer RR (1999) Targeted mutagenesis of the endogenous mouse Mis gene promoter: in vivo definition of genetic pathways of vertebrate sexual development Cell 99 409-419

Barbaux S, Niaudet P, Gubler MC et al. (1997) Donor splicesite mutations in WT1 are responsible for Frasier syndrome Nature Genetics 17 467-470

Bardeesy N and Pelletier J (1998) Overlapping RNA and DNA binding domains of the wt1 tumor suppressor gene product Nucleic Acids Research 26 1784-1792

Bardoni B, Zanaria E, Guioli S et al. (1994) A dosage sensitive locus at chromosome Xp21 is involved in male to female sex reversal Nature Genetics 7 497-501

Birk OS, Casiano DE, Wassif CA et al. (2000) The LIM homeobox gene Lhx9 is essential for mouse gonad formation Nature 403 909-913

Bishop CE, Whitworth DJ, Qin Y, Agoulnik AI, Agoulnik IU, Harrison WR, Behringer RR and Overbeek PA (2000) A transgenic insertion upstream of sox 9 is associated with dominant XX sex reversal in the mouse Nature Genetics 26 490-494

Buoen LC, Zhang TQ, Weber AF and Ruth GR (2000) SRYnegative, $\mathrm{XX}$ intersex horses: the need for pedigree studies to examine the mode of inheritance of the condition Equine Veterinary Journal 32 78-81

Calvari V, Bertini V, De Grandi A et al. (2000) A new submicroscopic deletion that refines the $9 p$ region for sex reversal Genomics 65 203-212

Cameron FJ and Sinclair AH (1997) Mutations in SRY and SOX9: testis-determining genes Human Mutation 9 388-395

Capel B, Albrecht KH, Washburn LL and Eicher EM (1999) Migration of mesonephric cells into the mammalian gonad depends on Sry Mechanisms of Development $\mathbf{8 4}$ $127-131$

Caricasole A, Duarte A, Larsson SH, Hastie ND, Little M, Holmes G, Todorov I and Ward A (1996) RNA binding by the Wilms tumor suppressor zinc finger proteins Proceedings National Academy of Sciences USA 93 7562-7566

Conley AJ, Corbin CJ, Hinshelwood MM, Liu Z, Simpson ER, Ford JJ and Harada N (1996) Functional aromatase expression in porcine adrenal gland and testis Biology of Reproduction 54 497-505

Daneau I, Ethier JF, Lussier JG and Silversides DW (1996) Porcine SRY gene locus and genital ridge expression Biology of Reproduction 55 47-53

De Felici M and Pesce M (1994) Growth factors in mouse primordial germ cell migration and proliferation Progress in Growth Factor Research 5135-143
Donovan PJ (1994) Growth factor regulation of mouse primordial germ cell development Current Topics in Developmental Biology 29 189-225

Dube JL, Wang P, Elvin J, Lyons KM, Celeste AJ and Matzuk MM (1998) The bone morphogenetic protein 15 gene is X-linked and expressed in oocytes Molecular Endocrinology 12 1809-1817

Durlinger AL, Kramer P, Karels B, de Jong FH, Uilenbroek JT, Grootegoed JA and Themmen AP (1999) Control of primordial follicle recruitment by anti-Mullerian hormone in the mouse ovary Endocrinology $\mathbf{1 4 0}$ 5789-5796

Edelmann W, Cohen PE, Kneitz B, Winand N, Lia M, Heyer J, Kolodner R, Pollard JW and Kucherlapati R (1999) Mammalian MutS homologue 5 is required for chromosome pairing in meiosis Nature Genetics 21 123-127

Ferguson-Smith MA (1966) X-Y chromosomal interchange in the aetiology of true hermaphroditism and of XX Klinefelter's syndrome Lancet 2 475-476

Foster JW, Dominguez-Steglich MA, Guioli S et al. (1994) Campomelic dysplasia and autosomal sex reversal caused by mutations in an SRY-related gene Nature 372 525-530

Galloway SM, McNatty KP, Cambridge LM et al. (2000) Mutations in an oocyte-derived growth factor gene (BMP15) cause increased ovulation rate and infertility in a dosage-sensitive manner Nature Genetics 25 279-283

Gessler M, Poustka A, Cavenee W, Neve RL, Orkin SH and Bruns GA (1990) Homozygous deletion in Wilms tumours of a zinc-finger gene identified by chromosome jumping Nature $343774-778$

Godin I, Deed R, Cooke J, Zsebo K, Dexter M and Wylie CC (1991) Effects of the steel gene product on mouse primordial germ cells in culture Nature 352 807-809

Graddy LG, Kowalski AA, Simmen FA, Davis SL, Baumgartner WW and Simmen RC (2000) Multiple isoforms of porcine aromatase are encoded by three distinct genes Journal of Steroid Biochemistry and Molecular Biology 73 49-57

Haber DA, Sohn RL, Buckler AJ, Pelletier J, Call KM and Housman DE (1991) Alternative splicing and genomic structure of the Wilms tumor gene WT1 Proceedings National Academy of Sciences USA 88 9618-9622

Habu T, Taki T, West A, Nishimune $Y$ and Morita T (1996) The mouse and human homologs of DMC1, the yeast meiosis-specific homologous recombination gene, have a common unique form of exon-skipped transcript in meiosis Nucleic Acids Research 24 470-477

Huang B, Wang S, Ning Y, Lamb AN and Bartley J (1999) Autosomal $\mathrm{XX}$ sex reversal caused by duplication of SOX9 American Journal of Medical Genetics 87 349-353

Ikeda Y, Shen WH, Ingraham HA and Parker KL (1994) 
Developmental expression of mouse steroidogenic factor1 , an essential regulator of the steroid hydroxylases Molecular Endocrinology 8 654-662

Jeske YW, Bowles J, Greenfield A and Koopman P (1995) Expression of a linear Sry transcript in the mouse genital ridge Nature Genetics 10 480-482

Jost A, Vigier B, Prépin J and Perchellet JP (1973) Studies on sex differentiation in mammals Recent Progress in Hormone Research 29 1-41

Katoh-Fukui Y, Tsuchiya R, Shiroishi T, Nakahara Y, Hashimoto $N$, Noguchi $K$ and Higashinakagawa $T$ (1998) Male-to-female sex reversal in M33 mutant mice Nature 393 688-692

Kent J, Wheatley SC, Andrews JE, Sinclair AH and Koopman P (1996) A male-specific role for SOX9 in vertebrate sex determination Development 122 2813-2822

Kettlewell JR, Raymond CS and Zarkower D (2000) Temperature-dependent expression of turtle Dmrt1 prior to sexual differentiation Genesis 26 174-178

Koopman P, Gubbay J, Vivian N, Goodfellow P and LovellBadge R (1991) Male development of chromosomally female mice transgenic for Sry Nature 351 117-121

Kreidberg JA, Sariola H, Loring JM, Maeda M, Pelletier J, Housman D and Jaenisch R (1993) WT-1 is required for early kidney development Cell 74 679-691

Lala DS, Rice DA and Parker KL (1992) Steroidogenic factor $\mathrm{I}$, a key regulator of steroidogenic enzyme expression, is the mouse homolog of fushi tarazu-factor I Molecular Endocrinology 6 1249-1258

Luo X, Ikeda Y and Parker KL (1994) A cell-specific nuclear receptor is essential for adrenal and gonadal development and sexual differentiation Cell 77 481-490

McElreavey K, Vilain E, Abbas N, Herskowitz I and Fellous M (1993) A regulatory cascade hypothesis for mammalian sex determination: SRY represses a negative regulator of male development Proceedings National Academy of Sciences USA 903368 - 3372

McGrath SA, Esquela AF and Lee SJ (1995) Oocyte-specific expression of growth/differentiation factor-9 Molecular Endocrinology 9131-136

Martineau J, Nordqvist K, Tilmann C, Lovell-Badge R and Capel B (1997) Male-specific cell migration into the developing gonad Current Biology 7 958-968

Meyers-Wallen VN, Schlafer D, Barr I, Lovell-Badge $\mathbf{R}$ and Keyzner A (1999) Sry-negative XX sex reversal in purebred dogs Molecular Reproduction and Development 53 266-273

Miyamoto N, Yoshida M, Kuratani S, Matsuo I and Aizawa S (1997) Defects of urogenital development in mice lacking Em×2 Development 124 1653-1664

Morais da Silva S, Hacker A, Harley V, Goodfellow P, Swain A and Lovell-Badge $\mathbf{R}$ (1996) Sox9 expression during gonadal development implies a conserved role for the gene in testis differentiation in mammals and birds Nature Genetics 14 62-68

Morohashi K, Honda S, Inomata Y, Handa H and Omura T (1992) A common trans-acting factor, Ad4-binding protein, to the promoters of steroidogenic $\mathrm{P}-450$ s Journal of Biological Chemistry 267 17913-17919

Nachtigal MW, Hirokawa Y, Enyeart-VanHouten DL, Flanagan IN, Hammer GD and Ingraham HA (1998)
Wilms' tumor 1 and Dax-1 modulate the orphan nuclear receptor SF-1 in sex-specific gene expression Cell 93 445-454

Ottolenghi C, Veitia R, Quintana-Murci L, Torchard D, Scapoli L, Souleyreau-Therville N, Beckmann J, Fellous $\mathbf{M}$ and McElreavey $\mathbf{K}$ (2000) The region on 9p associated with $46, X Y$ sex reversal contains several transcripts expressed in the urogenital system and a novel doublesex-related domain Genomics 64 170-178

Pailhoux E, Cribiu EP, Chaffaux S, Darre R, Fellous M and Cotinot C (1994a) Molecular analysis of 60,XX pseudohermaphrodite polled goats for the presence of SRY and ZFY genes Journal of Reproduction and Fertility $100491-496$

Pailhoux E, Popescu PC, Parma P, Boscher J, Legault C, Molteni L, Fellous M and Cotinot C (1994b) Genetic analysis of $38 \mathrm{XX}$ males with genital ambiguities and true hermaphrodites in pigs Animal Genetics 25 299-305

Pailhoux E, Pelliniemi L, Barbosa A, Parma P, Kuopio T and Cotinot C (1997) Relevance of intersexuality to breeding and reproductive biotechnology programs; $X X$ sex reversal in pigs Theriogenology 47 93-102

Parma P, Pailhoux E, Puissant C and Cotinot C (1997) Porcine Dax-1 gene: isolation and expression during gonadal development Molecular and Cellular Endocrinology $13549-58$

Parma P, Pailhoux E and Cotinot C (1999) Reverse transcription-polymerase chain reaction analysis of genes involved in gonadal differentiation in pigs Biology of Reproduction $61741-748$

Payen E, Pailhoux E, Abou Merhi R, Gianquinto L, Kirszenbaum M, Locatelli A and Cotinot C (1996) Characterization of ovine SRY transcript and developmental expression of genes involved in sexual differentiation International Journal of Developmental Biology 40 567-575

Pelletier J, Bruening W, Li FP, Haber DA, Glaser T and Housman DE (1991) WT1 mutations contribute to abnormal genital system development and hereditary Wilms' tumour Nature 353 431-434

Pelliniemi LJ (1985) Sexual differentiation of the pig gonad Archives d'Anatomie Microscopique et de Morphologie Expérimentale 74 76-80

Pelliniemi LJ and Lauteala L (1981) Development of sexual dimorphism in the embryonic gonad Human Genetics $5864-67$

Pfeifer D, Kist R, Dewar K, Devon K, Lander ES, Birren B, Korniszewski L, Back E and Scherer G (1999) Campomelic dysplasia translocation breakpoints are scattered over $1 \mathrm{Mb}$ proximal to SOX9: evidence for an extended control region American Journal of Human Genetics $65111-124$

Pilon N, Behdjani R, Daneau I, Lussier JG and Silversides DW (1998) Porcine steroidogenic factor-1 gene (pSF-1) expression and analysis of embryonic pig gonads during sexual differentiation Endocrinology 139 3803-3812

Pritchard-Jones K, Fleming S, Davidson D et al. (1990) The candidate Wilms' tumour gene is involved in genitourinary development Nature 346 194-197

Raeside II, Wilkinson CR and Farkas G (1993) Ontogenesis of estrogen secretion by porcine fetal testes Acta Endocrinologica 128 549-554 
Raymond CS, Shamu CE, Shen MM, Seifert KJ, Hirsch B, Hodgkin J and Zarkower D (1998) Evidence for evolutionary conservation of sex-determining genes Nature 391 691-695

Raymond CS, Kettlewell JR, Hirsch B, Bardwell VJ and Zarkower D (1999) Expression of Dmrt1 in the genital ridge of mouse and chicken embryos suggests a role in vertebrate sexual development Developmental Biology 215 208-220

Ruggiu M, Speed R, Taggart M, McKay SJ, Kilanowski F, Saunders P, Dorin J and Cooke HJ (1997) The mouse Dazla gene encodes a cytoplasmic protein essential for gametogenesis Nature 389 73-77

Sanchez A, Bullejos M, Burgos M, Hera C, Stamatopoulos C, Diaz De la Guardia R and Jimenez R (1996) Females of four mole species of genus Talpa (insectivora, mammalia) are true hermaphrodites with ovotestes Molecular Reproduction and Development 44 289-294

Sarafoglou K and Ostrer H (2000) Clinical review 111: familial sex reversal: a review Journal of Clinical Endocrinology and Metabolism 85 483-493

Shawlot W and Behringer RR (1995) Requirement for Lim1 in head-organizer function Nature 374 425-430

Shen WH, Moore CC, Ikeda Y, Parker KL and Ingraham HA (1994) Nuclear receptor steroidogenic factor 1 regulates the mullerian inhibiting substance gene: a link to the sex determination cascade Cell 77 651-661

Sinclair AH, Berta P, Palmer MS et al. (1990) A gene from the human sex-determining region encodes a protein with homology to a conserved DNA-binding motif Nature $346240-244$

Soyal SM, Amleh A and Dean J (2000) FIGalpha, a germ cellspecific transcription factor required for ovarian follicle formation Development 127 4645-4654

Südbeck P, Schmitz ML, Baeuerle PA and Scherer G (1996) Sex reversal by loss of the $\mathrm{C}$-terminal transactivation domain of human SOX9 Nature Genetics 13 230-232

Swain A, Zanaria E, Hacker A, Lovell-Badge R and Camerino G (1996) Mouse Dax1 expression is consistent with a role in sex determination as well as in adrenal and hypothalamus function Nature Genetics 12 404-409

Swain A, Narvaez V, Burgoyne P, Camerino G and LovellBadge R (1998) Dax1 antagonizes Sry action in mammalian sex determination Nature 391 761-767

Tilmann C and Capel B (1999) Mesonephric cell migration induces testis cord formation and Sertoli cell differentiation in the mammalian gonad Development 126 2883-2890

Vaiman D and Pailhoux E (2000) Mammalian sex reversal and intersexuality. Deciphering the sex-determination cascade Trends in Genetics 16 488-494

Vainio S, Heikkila M, Kispert A, Chin N and McMahon AP (1999) Female development in mammals is regulated by Wnt-4 signalling Nature 397 405-409

Wagner T, Wirth J, Meyer J et al. (1994) Autosomal sex reversal and campomelic dysplasia are caused by mutations in and around the SRY-related gene SOX9 Cell 79 1111-1120

Western PS, Harry JL, Graves JA and Sinclair AH (1999) Temperature-dependent sex determination: upregulation of SOX9 expression after commitment to male development Developmental Dynamics 214 171-177

Whitfield LS, Lovell-Badge R and Goodfellow PN (1993) Rapid sequence evolution of the mammalian sexdetermining gene SRY Nature $364713-715$

Whitworth DJ, Shaw G and Renfree MB (1996) Gonadal sex reversal of the developing marsupial ovary in vivo and in vitro. Development 122 4057-4063

Wunderle VM, Critcher R, Hastie N, Goodfellow PN and Schedl A (1998) Deletion of long-range regulatory elements upstream of SOX9 causes campomelic dysplasia Proceedings National Academy of Sciences USA $9510649-10654$

Yang H, Fries R and Stranzinger G (1993) The sexdetermining region $Y(S R Y)$ gene is mapped to p12-p13 of the $Y$ chromosome in pig (Sus scrofa domestica) by in situ hybridization Animal Genetics 24 297-300

Yu RN, Ito M, Saunders TL, Camper SA and Jameson JL (1998) Role of Ahch in gonadal development and gametogenesis Nature Genetics $20353-357$ 